\title{
Adjustable Spectral Characteristics to Design FIR Filter Using Two-Variable Window Function
}

Juhi Khan Afridi ${ }^{1}$, Awadhesh Gupta ${ }^{2}$ and Vandana Vikas Thakre ${ }^{3}$

${ }^{I}$ M.E. Scholar, Department of Electronics Engineering, MITS Gwalior, Gwalior, India, juhiafridi19@gmail.com

${ }^{2}$ Assistant Professor, Department of Electronics Engineering, MITS Gwalior, Gwalior, India, awadhesh2911@mitsgwalior.in

${ }^{3}$ Associate Professor, Department of Electronics Engineering, MITS, Gwalior, India, vandanavt_19@mitsgwalior.in

*Correspondence: Juhi Khan Afridi, MITS Gwalior, Gwalior, India, juhiafridi19@gmail.com

\begin{abstract}
This paper present a new dynamic window function having variable or adjustable spectral characteristics. A new dynamic window function proposed in this paper is a combination of hamming, Blackman-Harris, chebwin, and Kaiser Window function. Blackman-Harris, chebwin, and Kaiser Window functions have been used to compare with the suggested proposed window function i.e. a combination of hamming, Blackman-Harris, chebwin, and Kaiser Window function. Compare observation has been done with the help of MATLAB simulation. The simulation results show that the suggested proposed window function provides better ripple-ratio, main lobe width and side lobe roll-off ratio as compared to Blackman-Harris, chebwin, and Kaiser-window function. While comparing with Blackman-Harris, chebwin, and Kaiser Window functions, proposed window function provide quite good spectral performances with a very small compromisation of one of the spectral characteristics.
\end{abstract}

Keywords: FIR Filter, Window Function, Ripple-Ratio, Side-lobe Roll-Off Ratio, Main-lobe Width.

\section{INTRODUCTION}

For an input sequence $\mathrm{x}(\mathrm{n})$ with discrete-time, discrete-time filter generated an output sequence $y(n)$ with discrete-time. As know that filter has a device which gives us desirable outcomes in term of frequency and these discrete-time filters have been shown a lot of application like signal processing, suppression of noise and also an enhancement in images [1-2]

\section{ARTICLE INFORMATION}

Author(s); Juhi Khan Afridi, Awadhesh Gupta and Vandana Vikas Thakre

Received: 15 February 2020; Revision: 07 March 2020;

Published: 30 March 2020;

e-ISSN: 2347-470X; Paper Id-IJEER-080105;

Citation: http://doi.org/10.37391/IJEER.080103

Webpage-link: http://ijeer.forexjournal.co.in/archive/volume-8/ijeer080105.html

\begin{tabular}{|l|}
\hline CrOSSTef member \\
\hline CROSSREFORG \\
THECIATION LINKING BACKBONE \\
\hline
\end{tabular}

A Filter required may be required to have a given frequency response, or a specific response to an impulse, step, or ramp, or simulate an analogue system. Digital filters are categories either FIR or IIR, depending upon the form of the unit pulse response of the system. A digital FIR filter has a finite duration of the impulse response, it means the finite number of non-zero terms.
Assume that a system has an equation (difference) with input and output sequence $\mathrm{x}(\mathrm{n})$ and $\mathrm{y}(\mathrm{n})$ respectively define as follows;

$$
\sum_{k=0}^{N} a_{k} y(n-1)-\sum_{k=0}^{M} b_{k} x(n-k)
$$

M-length FIR filter is described as follows by the difference equation

$$
\begin{aligned}
& y(n)=b_{0} x(n)+b_{1} x(n-1)+b_{2} x(n-2)+\cdots \\
& \ldots \ldots+b_{M-1} x(n-M+1)=\sum_{k=0}^{M-1} b_{k} x(n-k)
\end{aligned}
$$

Where $\left\{b_{k}\right\}$ is the set of filter coefficient. So it is very clear from the above equation, the output response of the FIR filter depends upon only on the present and past input sample sequence.

The FIR filters exhibit exact linear phase and they are always stable, design methods are also generally linear, the filter start up transients have a finite duration and also realization in hardware so efficiently. Because of these advantages FIR filters are highly preferable if no phase distortion is required. There was the number of approaches presented by the 
researchers for design FIR filter and these approaches give us closed solutions [10].

Windowing is a process of truncation of the impulse response from infinite impulse response filter. Truncation of the impulse response from infinite impulse response filter is equal to the product of $h_{d}[n]$ and $w[n]$. Because of this digital FIR filter design using window approach is a better approach to design a finite impulse response filter. Generally, window function helps us to provide zero value outside the certain interval so can modify the value of adjustable window by modified the generally window function help us to provide zero value outside the certain interval so can modify the value of adjustable window by modifying the one or more variable parameters [2] [6]. This paper presents several windows for quite better spectral responses than commonly used windows.

The basic desirable need or requirement for implementing any window function, smaller main lobe width, high ripple ration (in a negative sense) and high side-lobe roll-off ratio [8]. But for some instances, these characteristics oppose each other and also shows some limitation like a window having higher side lobe has smaller main lobe width and vice versa [3-5].

There are three desired specifications for a window function which are defined as:

Main-lobe width $\left(\mathrm{W}_{\mathrm{B}}\right) \stackrel{\text { gaf }}{=}$ Width of the main-lobe $\mathrm{x} 2 \pi$

Ripple-Ratio (R) $\stackrel{\text { daf }}{=}$ Maximum side-lobe amplitude (in $\mathrm{dB}$ ) Main-lobe amplitude (in $\mathrm{dB})=\mathrm{S}_{1}$

Side-lobe roll-off ratio (S) $\stackrel{\text { at }}{=}$ Maximum side-lobe amplitude (in $\mathrm{dB}$ ) - Minimum side-lobe amplitude (in $\mathrm{dB})=\mathrm{S}_{1}-\mathrm{S}_{\mathrm{L}}$

A new dynamic window function proposed in this paper is a combination of hamming, Blackman-Harris, chebwin, and Kaiser Window function. Blackman-Harris, chebwin, and Kaiser Window functions have been used to compare with the suggested proposed window function i.e. a combination of hamming, Blackman-Harris, chebwin, and Kaiser Window function. Compare observation has been done with the help of MATLAB simulation.

This section of paper discusses the introductory part of FIR filter and their advantage and also discusses the window design approach, rest of the paper describe as follows, section II discusses the suggested proposed window function to design FIR filter and comparison discusses in the section 3 of this paper and last but not the least conclusion discusses in section 4.

\section{SUGGESTED WINDOW FUNCTION}

A new dynamic window function proposed in this paper is a combination of Blackman-Harris, hamming, Kaiser and chebwin-window function provided in equation respectively;

The function of the Blackman-Harris window given as;

$$
\begin{aligned}
& \mathrm{w}_{1}[\mathrm{n}]=0.35875 \quad 0.18829 \cos \left(\frac{2 \pi n}{N-1}\right) \| 0.14128 \\
& \cos \left(\frac{4 \pi n}{N-1}\right)-0.01168 \cos \left(\frac{6 \pi n}{N-1}\right)
\end{aligned}
$$

The function of the hamming window given as;

$\mathrm{w}_{2}[n]=0.54-0.46 \cos \left(\frac{2 \pi n}{N-1}\right)$

The function of Kaiser Window given as;

$w_{3}[n]=\frac{I_{0}\left(\pi \alpha \sqrt{1-\left(\frac{2 n}{N-1}\right)^{2}}\right)}{I_{0}(\pi \alpha)}$ for $0 \leq n \leq N-1$

Where $\mathrm{N}$ is the length of FIR filter require and $\mathrm{I}_{0}$ is the zerothorder modified Bessel function of the first kind and $\alpha$ is inverse of the standard deviation of Kaiser Window function.

The function of Chebwin Window given as;

$$
\mathrm{w}_{4}[n]=w_{0}\left(n-\frac{N-1}{2}\right) \text { for } 0 \leq n \leq N-1
$$

A new dynamic window function proposed is a combination of hamming, Blackman-Harris, chebwin, and Kaiser Window function. The suggested window functions are given by the equation below;

$\mathrm{w}[\mathrm{n}]=\left\{\begin{array}{cc}{\left[w_{2} w_{1}-w_{1}\right.} \\ 0\end{array}\left(\left(\frac{1}{\mathrm{a}}\right)\left(\cosh \left(w_{3}\right)\right)^{\mathrm{d} 1} w_{4}\right\} w_{4}\right]^{\mathrm{r}} \quad \begin{gathered}0 \leq n \leq N-1 \\ \text { otherwise }\end{gathered}$

Where ' $a$ ' setup the gain of the window and ' $r$ ' is the spectral control parameter.

\section{RESULTS \& DISCUSSION}

A new dynamic window function proposed in this paper is a combination of Blackman-Harris, hamming, Kaiser and chebwin Window function provided in the equation as follows;

$w[n]-\left\{\left[w_{2} w_{1}-w_{1}\left\{\left(\frac{1}{a}\right)\left(\operatorname{rosh}\left(w_{3}\right)\right)^{0.1} w_{4}\right\} w_{4}\right]^{r} \begin{array}{c}0<n<N-1 \\ 0 \\ \text { otherwse }\end{array}\right.$ 


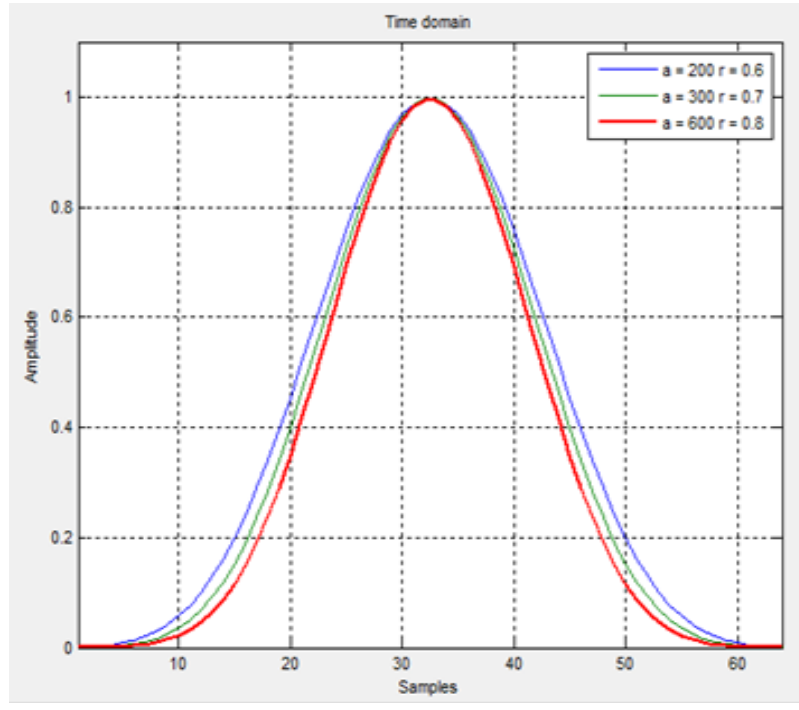

Figure 1: Time Domain Characteristic of suggested proposed window for the specific value of ' $a$ ' and ' $r$ '

As above depicted figure 1 shows that the time domain characteristics and frequency domain characteristics of the suggested window for the specific value of ' $a$ ' and ' $r$ '.

The figure 1 shows the time domain characteristics of proposed window for ' $a$ ' $=200,300,600$ respectively and value of ' $r$ ' $=0.6,0.7,0.8$ respectively, from the time domain characteristics graph shows that the proposed window achieved minimum width for ' $\mathrm{a}$ ' $=600$ and ' $\mathrm{r}$ ' $=0.8$, as results reduction of window width in time domain characteristics cause higher main lobe width in frequency domain characteristics.

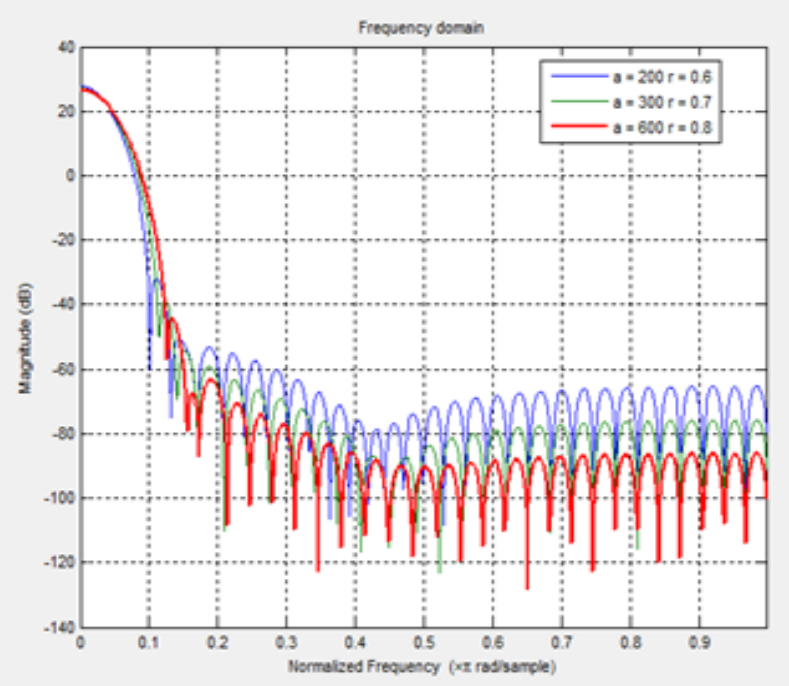

Figure 2: Frequency Domain Characteristic of the suggested window for the specific value of ' $a$ ' and ' $r$ '.
As above depicted figure 2 shows that the frequency domain characteristics of the suggested window for the different specific value of ' $a$ ' and ' $r$ '. The figure shows the frequency domain characteristics of proposed window for ' $a$ ' $=200,300$, 600 and value of ' $r$ ' $=0.6,0.7,0.8$ respectively, from the frequency domain characteristics graph shows that the proposed window achieved better performance for ' $a$ ' $=600$ and ' $r$ ' $=0.8$.

Table 1: Frequency Domain Characteristics of Suggested window for Specific 'a' and ' $r$ '

\begin{tabular}{|l|l|l|l|}
\hline $\begin{array}{l}\text { Adjustable } \\
\text { Parameter } \\
\text { 'a' and 'r' }\end{array}$ & $\begin{array}{l}\text { Main } \\
\text { Lobe } \\
\text { Width } \\
\text { (MLW) }\end{array}$ & $\begin{array}{l}\text { Ripple } \\
\text { Ratio } \\
\text { (RR in } \\
\text { dB) }\end{array}$ & $\begin{array}{l}\text { Side-lobe Roll- } \\
\text { off Ratio (SLRR } \\
\text { in dB) }\end{array}$ \\
\hline $\begin{array}{l}\mathrm{a}=200, \mathrm{r}= \\
0.6\end{array}$ & $\begin{array}{l}0.1015 \times \\
2 \pi\end{array}$ & -59.50 & 46.062 \\
\hline $\begin{array}{l}\mathrm{a}=300, \mathrm{r}= \\
0.7\end{array}$ & $\begin{array}{l}0.1152 \times \\
2 \pi\end{array}$ & -64.09 & 49.777 \\
\hline $\begin{array}{l}\mathrm{a}=600, \mathrm{r}= \\
0.8\end{array}$ & $\begin{array}{l}0.1250 \times \\
2 \pi\end{array}$ & -71.00 & 45.878 \\
\hline
\end{tabular}

Figure 1 shows that the while increasing ' $a$ ' and ' $r$ ' the reduction of window width achieved in the time domain but the reduction of window width in time domain cause higher main-lobe in the frequency domain as shown in figure 2 . It is also clear from table 1 and figure 2, increases the ' $a$ ' and ' $r$ ' increase the value of $R R$ in the negative sense but SLRR increases up-to some extent than decreases.

This section of the paper presents a comparative analysis of suggested proposed window with black-man Harris, Kaiser and Chebwin window function.

\subsection{Black-man Harris Window:}

The Black-man Harris window function is defined as the equation below;

$$
\begin{aligned}
\mathrm{w}_{1}[\mathrm{n}]= & 0.35875-0.48829 \cos \left(\frac{2 \pi n}{N-1}\right)+0.14128 \\
& \cos \left(\frac{4 \pi n}{N-1}\right)-0.01168 \cos \left(\frac{6 \pi n}{N-1}\right)
\end{aligned}
$$




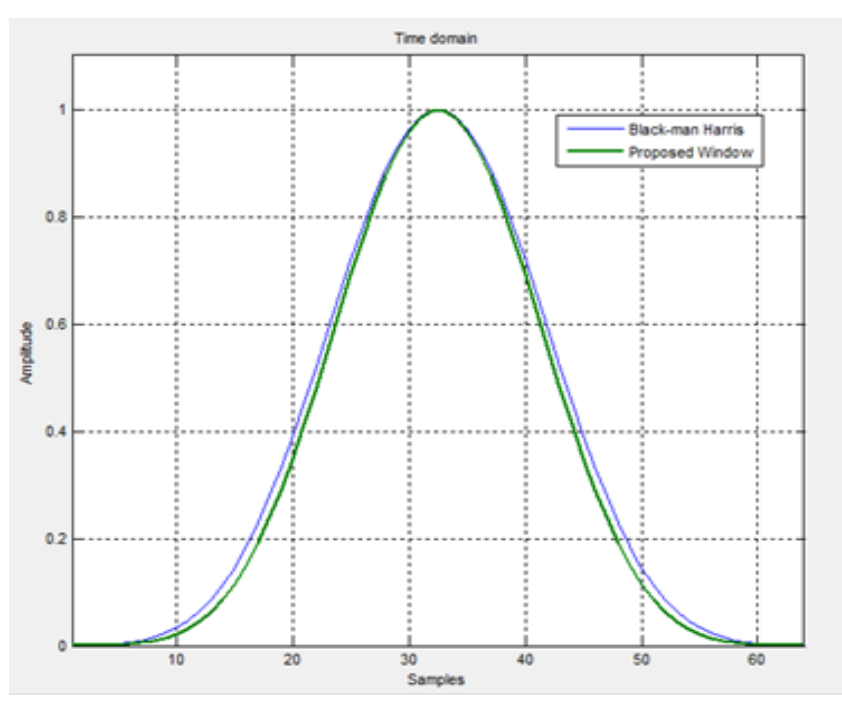

Figure 3: Time Domain Comparative Analysis of Proposed Window with Black-man Harris

As above depicted figure 3 shows that the time domain characteristics for Black-man Harris and Proposed suggested window technique and the proposed window technique provide less window width as compared to Black-man Harris window in the time domain but it causes higher MLW in frequency domain characteristics.

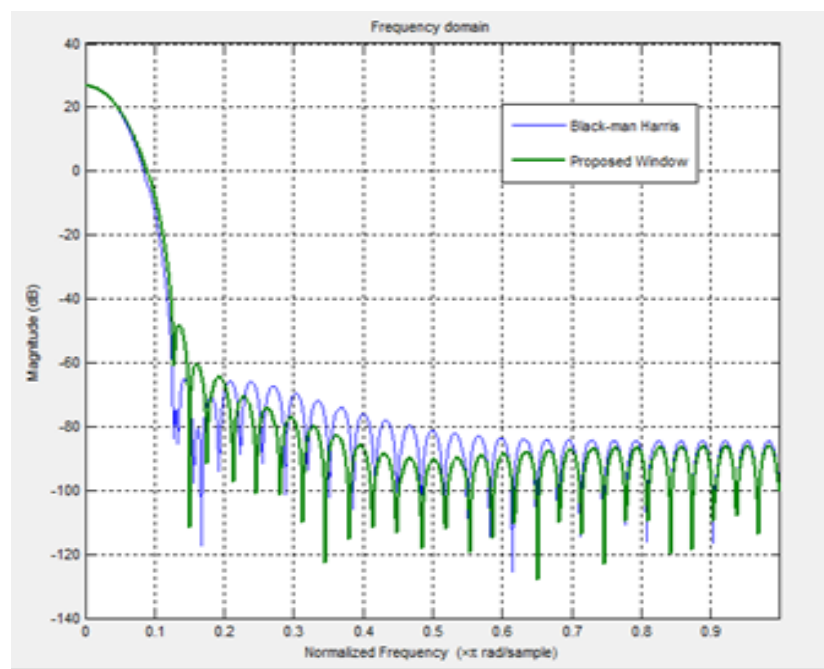

Figure 4: Frequency Domain Comparative Analysis of Proposed Window with Black-man Harris

As below depicted figure 4 shows that the frequency domain characteristics of the suggested window for the different specific value of ' $a$ ' $=600$ and ' $r$ ' $=0.8$ and Black-man Harris Window. The figure shows the frequency domain characteristics of the proposed window for ' $a$ ' $=600$ and the value of ' $r$ ' $=0.8$ achieved better performance in term of SLRR and MLW but there is approx. $18 \mathrm{~dB}$ compromisation in RR.
Table 2: Frequency Domain Characteristics comparison of Proposed Window with Black-man Harris

\begin{tabular}{|l|l|l|l|}
\hline $\begin{array}{l}\text { Window } \\
\text { Function }\end{array}$ & $\begin{array}{l}\text { Main } \\
\text { Lobe } \\
\text { Width } \\
\text { (ML) }\end{array}$ & $\begin{array}{l}\text { Ripple } \\
\text { Ratio } \\
\text { (RR in } \\
\text { dB) }\end{array}$ & $\begin{array}{l}\text { Side-lobe } \\
\text { Roll-off } \\
\text { Ratio } \\
\text { (SLRR in } \\
\text { dB) }\end{array}$ \\
\hline $\begin{array}{l}\text { Black-man } \\
\text { Harris Window } \\
\text { Function }\end{array}$ & $\begin{array}{l}0.1296 \times \\
2 \pi\end{array}$ & -93.48 & 30.771 \\
\hline $\begin{array}{l}\text { Proposed } \\
\text { Window } \\
\text { Function } \\
\mathrm{a}=600, \mathrm{r}=0.8\end{array}$ & $\begin{array}{l}0.1250 \times \\
2 \pi\end{array}$ & -75.11 & 45.878 \\
\hline
\end{tabular}

As above depicted table 2 shows that suggested window $(\mathrm{a}=600, \mathrm{r}=0.8)$ gives smaller main-lobe width, smaller and higher side-lobe roll-off ratio as compared to Black-man Harris window as desired. But there is compromisation of 18 $\mathrm{dB}$ in $\mathrm{RR}$ in negative-sense.

\subsection{Kaiser Window Function}

Kaiser window function is defined as:

$$
W_{a}[n]=\frac{I_{0}\left(\pi \alpha \sqrt{1-\left(\frac{2 n}{N-1}\right)^{2}}\right)}{I_{0}(\pi \alpha)} \text { for } 0 \leq n \leq N-1
$$

Where the zero-order is modified Bessel function of the first kind.

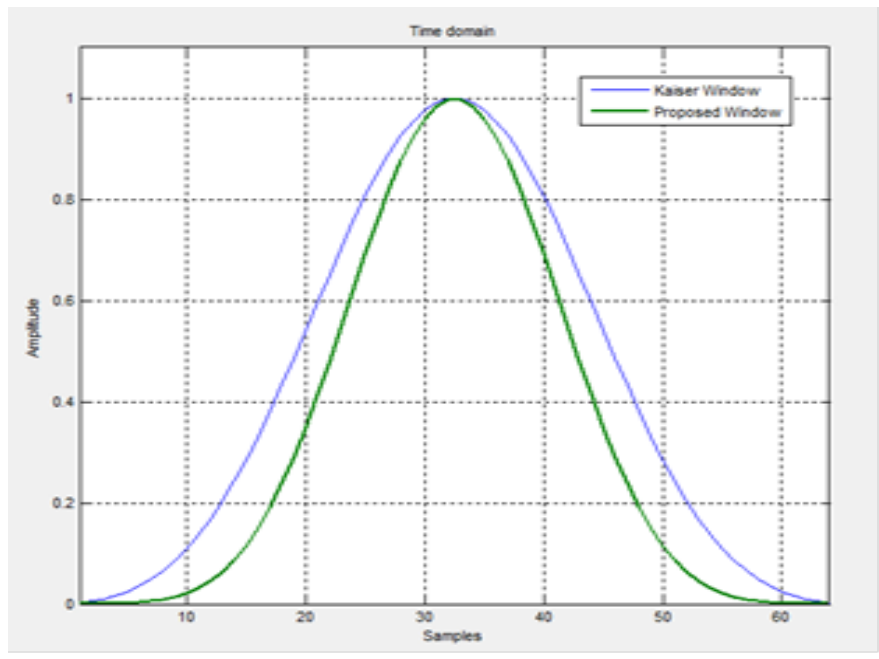

Figure 5: Time Domain Comparative Analysis of Proposed Window with Kaiser Window Function. 
As above depicted figure 5 shows that the time domain characteristics for Kaiser and Proposed suggested window technique and the proposed window technique provide less window width as compared to Kaiser Window in the time domain but it causes higher MLW in frequency domain characteristics.

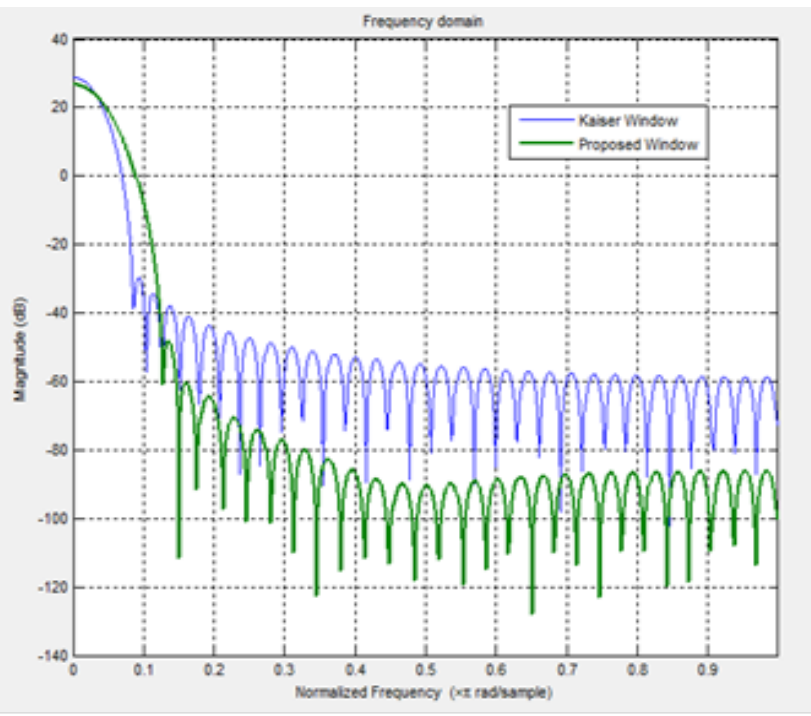

Figure 6: Frequency Domain Comparative Analysis of Proposed Window with Kaiser Window Function

As above depicted figure 6 shows that the frequency domain characteristics of the suggested window for the different specific value of ' $a$ ' $=600$ and ' $r$ ' $=0.8$ and Kaiser Window. The figure shows the frequency domain characteristics of the proposed window for ' $a$ ' $=600$ and value of ' $r$ ' $=0.8$ achieved better performance in term of SLRR and RR.

Table 3: Frequency Domain Characteristics comparison of Proposed Window with Kaiser Harris

\begin{tabular}{|l|l|l|l|}
\hline $\begin{array}{l}\text { Window } \\
\text { Function }\end{array}$ & $\begin{array}{l}\text { Main Lobe } \\
\text { Width } \\
\text { (MLW) }\end{array}$ & $\begin{array}{l}\text { Ripple } \\
\text { Ratio (RR } \\
\text { in dB) }\end{array}$ & $\begin{array}{l}\text { Side-lobe Roll- } \\
\text { off Ratio } \\
\text { (SLRR in dB) }\end{array}$ \\
\hline $\begin{array}{l}\text { Kaiser } \\
\text { Window } \\
\text { Function }\end{array}$ & $0.08593 \times$ & -58.30 & 27.467 \\
\hline $\begin{array}{l}\text { Proposed } \\
\text { Window } \\
\text { Function } \\
\mathrm{a}=600, \mathrm{r} \\
=0.8\end{array}$ & $0.1250 \times 2 \pi$ & -77.31 & 45.878 \\
\hline
\end{tabular}

As above depicted table 3 shows that suggested window $(\mathrm{a}=600, \mathrm{r}=0.8$ ) gives smaller ripple-ratio and higher side-lobe roll-off ratio compared to Kaiser Window as desired.

\subsection{Chebwin Window Function}

Chebwin window function is defined as:

$\mathrm{w}_{4}[n]=w_{0}\left(n-\frac{N-1}{2}\right)$ for $0 \leq n \leq N-1$

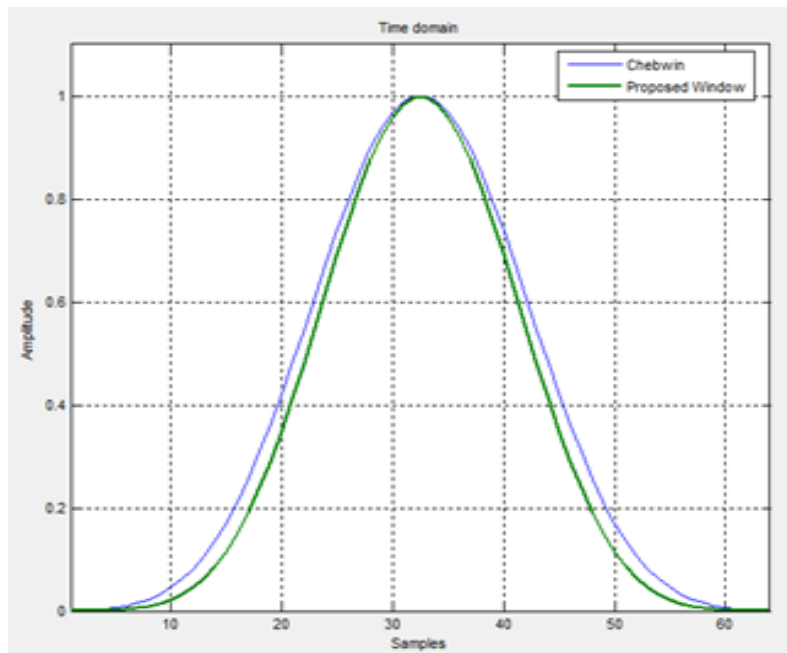

Figure 7: Time Domain Comparative Analysis of Proposed Window with Chebwin Window Function

As above depicted figure 7 shows that the time domain characteristics for Chebwin and Proposed suggested window technique and the proposed window technique provide less window width as compared to Chebwin Window in the time domain but it causes higher MLW in frequency domain characteristics

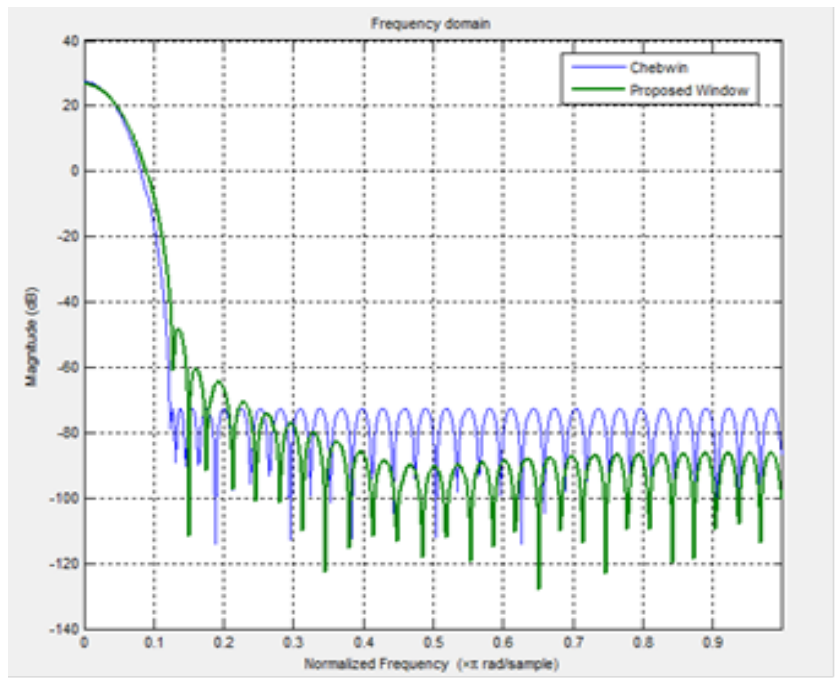

Figure 8: Frequency Domain Comparative Analysis of Proposed Window with Chebwin Window Function 
As above depicted figure 8 shows that the frequency domain characteristics of the suggested window for the different specific value of ' $a$ ' $=600$ and ' $r$ ' $=0.8$ and Chebwin Window. The figure shows the frequency domain characteristics of the proposed window for ' $a$ ' $=600$ and value of ' $r$ ' $=0.8$ achieved better performance in term of SLRR and MLW but there is $25 \mathrm{~dB}$ in $\mathrm{RR}$ compromisation in the negative sense.

Table 4: Frequency Domain Characteristics comparison of Proposed Window with Chebwin Window Function

\begin{tabular}{|l|l|l|l|}
\hline $\begin{array}{l}\text { Window } \\
\text { Function }\end{array}$ & $\begin{array}{l}\text { Main Lobe } \\
\text { Width } \\
\text { (MLW) }\end{array}$ & $\begin{array}{l}\text { Ripple } \\
\text { Ratio } \\
\text { (RR in } \\
\text { dB) }\end{array}$ & $\begin{array}{l}\text { Side-lobe Roll- } \\
\text { off Ratio } \\
\text { (SLRR in dB) }\end{array}$ \\
\hline $\begin{array}{l}\text { Chebwin } \\
\text { Window } \\
\text { Function }\end{array}$ & $0.1230 \times 2 \pi$ & -99.45 & 38.780 \\
\hline $\begin{array}{l}\text { Proposed } \\
\text { Window } \\
\text { Function } \\
\mathrm{a}=600, \mathrm{r}= \\
0.8\end{array}$ & $0.1250 \times 2 \pi$ & -74.67 & 45.878 \\
\hline
\end{tabular}

As above depicted table 4 shows that suggested window $(a=600, r=0.8)$ gives smaller main-lobe width and higher sidelobe roll-off ratio compared to Chebwin window as desired. But there is a compromisation of $25 \mathrm{~dB}$ in RR.

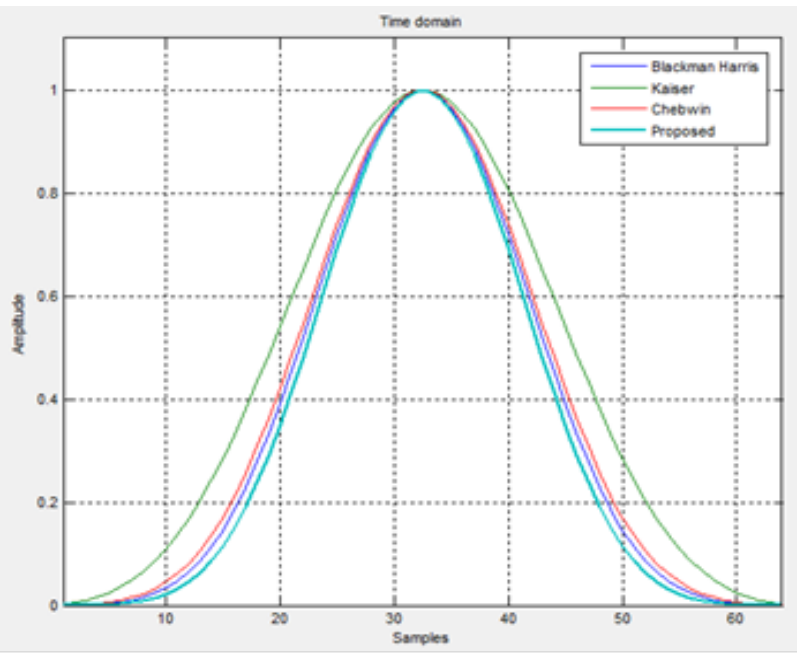

Figure 9: Time Domain Comparative Analysis of Proposed Window with Blackman Harris, Kaiser and Chebwin Window Function

As above depicted figure 9 shows that the Time Domain Comparative Analysis of Proposed Window with Blackman Harris, Kaiser and Chebwin Window Function and the proposed window technique provide less window width as compared to Black-man Harris, Kaiser and Chebwin Window in the time domain but it causes higher MLW in frequency domain characteristics.

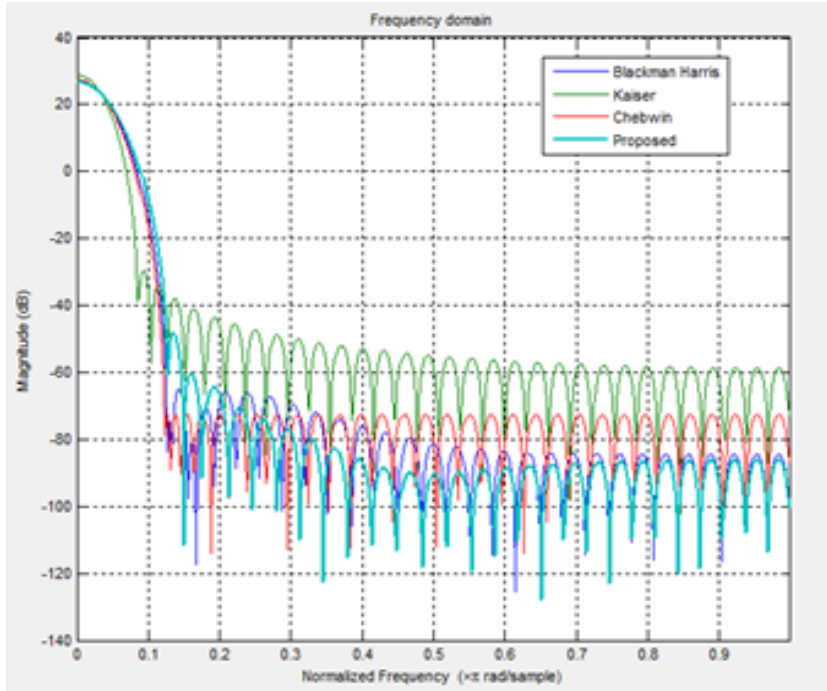

Figure 10: Frequency Domain Comparative Analysis of Proposed Window with Blackman Harris, Kaiser and Chebwin Window Function

Table 5: Frequency Domain Characteristics comparison of Proposed Window with Black-man Harris, Kaiser and Chebwin Window

\begin{tabular}{|l|l|l|l|}
\hline $\begin{array}{l}\text { Window } \\
\text { Function }\end{array}$ & $\begin{array}{l}\text { Main Lobe } \\
\text { Width } \\
\text { (MLW) }\end{array}$ & $\begin{array}{l}\text { Ripple } \\
\text { Ratio (RR } \\
\text { in dB) }\end{array}$ & $\begin{array}{l}\text { Side-lobe } \\
\text { Roll-off } \\
\text { Ratio(SLRR } \\
\text { in dB) }\end{array}$ \\
\hline $\begin{array}{l}\text { Black-man } \\
\text { Harris } \\
\text { Window } \\
\text { Function }\end{array}$ & $0.1296 \times 2 \pi$ & -93.48 & 30.771 \\
\hline $\begin{array}{l}\text { Chebwin } \\
\text { Window } \\
\text { Function }\end{array}$ & $0.1280 \times 2 \pi$ & -99.45 & 38.780 \\
\hline $\begin{array}{l}\text { Kaiser } \\
\text { Window } \\
\text { Function }\end{array}$ & $0.08593 \times 2 \pi$ & -58.30 & 27.467 \\
\hline $\begin{array}{l}\text { Proposed } \\
\text { Window } \\
\text { Function }= \\
600, \mathrm{r}=0.8\end{array}$ & $0.1250 \times 2 \pi$ & -77.31 & 45.878 \\
\hline
\end{tabular}

As above depicted figure 10 and table 5 shows that the comparative analysis of frequency-domain characteristics of the suggested window for the different specific value of ' $a$ ' = 600 and ' $r$ ' $=0.8$ with Black-man Harris, Kaiser and Chebwin 
Window technique. The suggested window provide less window width as compare Black-man Harris and Chebwin window but more than Kaiser Window. The suggested window shows overall better performance in terms of SLRR as compare to other window techniques and gives higher SLRR as compared to other window function techniques (i.e. Blackman Harris, Chebwin and Kaiser Window) but the suggested window compromise approx. $18 \mathrm{~dB}$ in RR of Black-man Harris and $25 \mathrm{~dB}$ in $\mathrm{RR}$ of Chebwin window.

\section{CONCLUSION}

The proposed window function can adjust the spectral characteristics i.e. ripple-ratio main-lobe width, and side-lobe roll-off by using two adjustable parameters ' $a$ ' and ' $r$ '. It shows better performance than Kaiser Window in term of SLRR and RR. The proposed window has better main-lobe width and SLRR than Blackman Harris Window but with a compromisation of ripple ratio (approx. $18 \mathrm{~dB}$ ). While comparing with Chebwin window we have concluded that the proposed window gives better main-lobe width and SLRR and but with a compromisation of approx. $25 \mathrm{~dB}$ in $\mathrm{RR}$.

\section{REFERENCES}

[1] T. Karmaker, M. S. Anower, M. A. G. Khan and M. A. Habib, "A new adjustable window function to design FIR filter and its application in noise reduction from contaminated ECG signal," 2017 IEEE Region 10 Humanitarian Technology Conference (R10-HTC), Dhaka, 2017, pp. 51-54.

[2] H. Rakshit and M. A. Ullah, "An adjustable novel Window function with its application to FIR filter design," in Proceedings of International Conference on Computer and Information Engineering (ICCIE), 2015, pp. 36-41.

[3] A. Nuttall, "Some windows with very good sidelobe behaviour,", IEEE Transactions on Acoustics, Speech, and Signal Processing, Vol. ASSP29, No. 1, Feb. 1981, pp. 84-91.

[4] Y. H. Ha and J. A. Pearce, "A new window and comparison to standard windows," IEEE Transactions on Acoustics, Speech, and Signal Processing, vol. 37, no. 2, Feb. 1989, pp. 298-301.

[5] R. A. Roberts and C.T. Mullis, Digital Signal Processing, Addison-Wesley, Jan. 1987, pp. 135-136.

[6] M. Shil, H. Rakshit and H. Ullah, "An adjustable window function to design an FIR filter," in proceedings of IEEE International Conference on Imaging, Vision \& Pattern Recognition (icIVPR), 2017, pp. 1-5.

[7] M. Khatun, "Implement a new window function and design FIR filters by using this new window," IJECS, Vol. 3, Issue 3, Mar. 2014, pp. 4087-4090

[8] A. Oppenheim, R. Schafer, and J. Buck, Discrete-Time Signal Processing, Prentice-Hall, second edition, 1999.

[9] J. F. Kaiser and R.W. Schafer (1980), "on the use of the I0-sinh window for spectrum analysis," IEEE Transactions on Acoustics, Speech, and Signal Processing, vol.28, no. 1, 1980, pp.105-107.

[10] J. Proakis and D. G. Manolakis, Digital Signal Processing, Prentice-Hall, fourth edition, 2007.

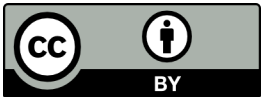

Attribution
(C) 2020 by the authors. Submitted for possible open access publication under the terms and conditions of the Creative Commons (CC BY) license 